\title{
Pulmonary manifestations in Behçet disease: impaired natural killer cells activity
}

\author{
Kamel Hamzaoui ${ }^{1 *}$, Anissa Berraies ${ }^{1,2}$, Wajih Kaabachi ${ }^{1}$, Jamel Ammar ${ }^{1,2}$ and Agnès Hamzaoui ${ }^{1,2}$
}

\begin{abstract}
Background: Behçet's disease (BD) is a systemic vasculitis with unknown aetiology, where, besides genetic predisposition, an immune dysregulation involving $T$ and $B$ lymphocytes and hyperactive neutrophils contribute to disease pathogenesis. The aim of this study was to determine the cytotoxicity of natural killer (NK) cells in bronchoalveolar lavage (BAL) from BD patients with pulmonary manifestations.

Methods: BAL was performed in 27 patients with BD and pulmonary manifestations, 14 patients with Rheumatoid Arthritis (RA) and 23 healthy controls (HC). Related orphan receptor C (RORC) and forkheadbox P3 (FOXP3) mRNA transcript were determined in BAL by reverse transcription-polymerase chain reaction (RT-PCR). NK cells, NK cell cytotoxicity, and lymphokine-activated killer (LAK) activity against K562 cells were measured by flow cytometry. Proportions of NK precursors and expression of genes for IL-2 receptor $\beta$ (IL-2RB; CD122), perforin, and granzyme in NK cells were measured by flow cytometry or RT-PCR.

Results: The analysis of transcription factors revealed an increase in the RORC/FOXP3 ratio (Th17/Treg cells) in BAL from BD patients. Percentages of NK were significantly lower in BD than in RA patients and healthy controls. Purified NK cells derived from BD patients were found to have lower cytotoxicity and LAK activity than those from controls. This defect of NK cells in BD patients was related to down-regulation of perforin and granzyme expression in NK cells.
\end{abstract}

Conclusion: In BD patients, the increased RORC/FOXP3 ratio indicated an inflammatory state of the lung. NK cells were decreased together with an impairment of their activity due to a defective expression of granzyme and perforin. These abnormalities possibly contribute to immune system dysregulation found in BAL of BD patients with pulmonary manifestations.

Keywords: Behçet disease, Bronchoalveolar lavage, Granzyme, Inflammation, Natural killer cells, Perforin

\section{Background}

Behçet's disease (BD) is a systemic vasculitis with unknown aetiology. Immune dysregulation involving $\mathrm{T}$ and $B$ cells with hyperactive neutrophils, supposedly triggered by infectious agents, contribute to disease pathogenesis in addition to genetic predisposition [1]. Documentation of various atypical streptococcal species in oral flora of $\mathrm{BD}$ patients, clinical flares after dental procedures and a good response to antibacterial treatment have been considered as evidence for the role of Streptococcus in BD [2]. However, none of the microbial agents has been

\footnotetext{
* Correspondence: kamel.hamzaoui@gmail.com

'Department of Basic Sciences, Division of Histology and Immunology, Medicine School of Tunis, Tunis El Manar University, 15 Rue DjebelLakdar, 1007 Tunis, Tunisia

Full list of author information is available at the end of the article
}

definitely proved to cause $\mathrm{BD}$. Immunological disorders are important in $\mathrm{BD}$ pathogenesis [3]. T lymphocytes from patients with $\mathrm{BD}$ produced a particular pattern of inflammatory mediators when stimulated with a bacterial superantigen, and innate immunity was deeply investigated in BD patients [4].

In Behçet's disease, vascular system involvement is the main cause of mortality. Pulmonary artery aneurysms, arterial and venous thrombosis, pulmonary infarction, recurrent pneumonia, bronchiolitis obliterans organized pneumonia, and pleurisy are the main features of pulmonary involvement in $\mathrm{BD}[5,6]$. Inflammatory features characterize bronchoaveolar lavage (BAL) from $\mathrm{BD}$ patients with pulmonary involvement. B cell-activating factor of the TNF family (BAFF), an important regulator of

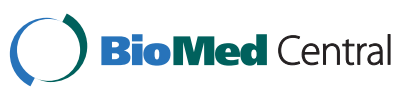


B-cell survival and immunoglobulin class-switch recombination is increased in BD lung and contributes to immunoglobulin synthesis [7]. Both interleukin 18 (IL-18) and gamma interferon (IFN- $\gamma$ ), contribute to the local inflammatory response in BAL from BD patients [8]. Recently Toll-like receptors expressing cells and NOD-like receptors (NLRs) were found to synergize for the induction of proinflammatory cytokines in BAL from BD patients with pulmonary manifestations [9].

As major components of innate immunity, Natural killer (NK) cells not only exert cell-mediated cytotoxicity against tumour or infected cells, but also regulate other immune cells functions by secretion of cytokines and chemokines. Due to these effector functions, NK cells play a significant role in host defense against malignancies and certain viruses and they may also be important in the regulation of autoimmunity [10]. However, the effector function of NK cells must be exquisitely controlled in order to prevent inadvertent attack against self normal cells. Patients with active BD show impaired NK cytotoxicity [11-14]. Impaired NK cytotoxicity in first-degree relatives of BD patients was recently reported [14-16], which suggests that NK cell deficiency, may be a genetic determinant of $\mathrm{BD}$.

The aim of the present study was to determine the expression of retinoid-related orphan receptor C (RORC) (Th17), forkheadbox P3 (FOXP3) (Treg) and the cytotoxicity of pulmonary NK cells in BD. We determined NK cell levels, NK cytotoxicity, and lymphokine-activated killer (LAK) activity in BAL of patients with BD. Proportions of NK precursors and expression of genes for IL-2 receptor $\beta$-chain (IL-2R $\beta$; CD122), perforin, and granzyme in NK cells were measured by flow cytometry or reverse transcription-polymerase chain reaction (RT-PCR).

\section{Methods}

\section{Patients}

The study group consisted of 27 BD patients (19 males, 8 females, age $34 \pm 10$ years; range $17-56$ years) all fulfilling the international study group criteria for Behcet's disease [17], with a disease duration ranging from 1 to 9 years (mean \pm SD: $5.8 \pm 3.4$ ). Twenty three BD patients were never-smokers and 4 ex-smokers. All patients had active BD with pulmonary manifestations [8,9] including eye lesions (14 patients: $51.85 \%)$, oral ulcers (27 patients: $100 \%)$, genital ulcers (18 patients: 66.67\%), arthritis (16 patients: 59.25\%), and vascular symptoms (12 patients: 44.45\%). Pulmonary vascular abnormalities were as follows: asymptomatic functional abnormalities (8 patients), pulmonary artery aneurysm (6 patients), pulmonary artery embolism (9 patients), and pulmonary venous abnormalities (4 patients). They were treated with steroids and colchicine. Remission was defined when clinical manifestations were lost (eye lesions, oral and genital ulcers, and arthritis). Asymptomatic functional abnormalities diminished after corticosteroid treatment. Rheumatoid arthritis patients (RA: 10 men and 4 women; mean age: $46.2 \pm 9.5$ years; range: $42-50$ years) acted as control disease. The control subjects consisted of 23 non-smokers (18 men and 5 women; mean age: $42.8 \pm 7$ years; range: $38-52$ years) undergoing routine investigations for suspected bronchial carcinoma and whose chest X-ray, bronchial examination, and pulmonary function were normal. None of them had evidence of acute infection or chronic disease (e.g., other autoimmune or atopic disorders). Our hospital ethic committee approved the design of the study and BAL was obtained after informed consent.

\section{Monoclonal antibodies (mAb) and flow cytometry}

The following $\mathrm{mAb}$ and reagents were used in this study: fluorescein isothiocyanate (FITC)-conjugated or peridinin chlorophyll A protein-conjugated antiCD3 mAb, FITC-conjugated anti-CD45 mAb, FITCconjugated or phycoerythrin (PE)-conjugated anti-CD56 $\mathrm{mAb}$, PE-conjugated anti-CD16 mAb, PE-conjugated anti-CD122 mAb, and FITC-conjugated antiperforinmAb (all from Becton Dickinson, San Diego, CA). Cells were stained with combinations of appropriate mAb at $4^{\circ} \mathrm{C}$ for 20 minutes. Stained cells were analyzed on a FACsCalibur flow cytometer using Cell Quest software (BD Biosciences, Mountain View, CA).

\section{Bronchoalveolar lavage}

BAL was obtained as we previously reported [9]. Briefly, bronchoscopy was performed according to standard guidelines [18]. Thirty minutes prior to the procedure patients received $0.5 \mathrm{mg}$ of atropine and $12.5 \mathrm{mg}$ codeine intramuscularly. Local anaesthesia of the oropharynx was achieved by xylocaine instillation until gag reflexes subsided. Bronchoscopy was performed using a Pentax bronchoscope through which $150 \mathrm{ml}$ of normal prewarmed saline in aliquots of $50 \mathrm{ml}$ were instilled into a subsegment of the right middle lobe. BAL fluid (BALF) was then immediately aspirated by gentle hand suction into plastic tubes and kept at $4^{\circ} \mathrm{C}$ on ice.

BALF was concentrated 10 fold before analysis whilst a great part of the cell pellets were immediately fixed in RNA stabilisation buffer. The total count of nucleated cells was performed as we have recently reported [9]. Differential cell count was determined by cytological examination of at least 500 cells after centrifugation in a cytospin (Shandon) and May-Grünwald-Giemsa staining. Cell percentages were recorded for every patient. The rest of BALF was centrifuged at $400 \mathrm{~g}$ for $10 \mathrm{~min}$ and the pellet was processed for lymphocyte subset of (Th17) and regulatory $\mathrm{T}$ cells (Treg) determination. All BALF were analyzed at the time of processing and only technically appropriate BALF were retrospectively reviewed. 


\section{Flow cytometric assays of the cytotoxicities of BAL cells and purified NK cells}

BAL cells and BAL-isolated NK cells were used as effector cells and were cultured for 4 hours at $37^{\circ} \mathrm{C}$ in complete media, consisting of RPMI 1640, 2 mM-glutamine, $100 \mathrm{units} / \mathrm{ml}$ of penicillin, $100 \mu \mathrm{g} / \mathrm{ml}$ of streptomycin, and supplemented with 10\% fetal bovine serum (FBS; Gibco BRL, Grand Island, NY) in a humidified incubator containing 5\% $\mathrm{CO}_{2}$. $\mathrm{K} 562$ cells (CCL-243; American Type Culture Collection, Manassas, VA) were used as target cells. Effector and target cells were mixed in $12 \times$ $75-\mathrm{mm}$ round-bottomed polystyrene tubes (Becton Dickinson) at different effector-to-target (E:T) cell ratios. Control tubes including only target cells were also assayed to quantify spontaneous $\mathrm{K} 562$ cell death. Tubes were incubated for 4 hours at $37^{\circ} \mathrm{C}$ in a humidified incubator containing $5 \% \mathrm{CO}_{2}$.

To determine LAK activities, $200 \mathrm{IU} / \mathrm{ml}$ of recombinant IL-2 (BD PharMingen, San Jose, CA) was added to the tubes. Mixed effector and target cells were stained with FITC-conjugated anti-CD45 $\mathrm{mAb}$ at $4^{\circ} \mathrm{C}$ for $20 \mathrm{mi}$ nutes, washed once in phosphate buffered saline (PBS), resuspended in $0.5 \mathrm{ml}$ of PBS containing $20 \mu \mathrm{l}$ of $1 \mu \mathrm{g} / \mathrm{ml}$ propidium iodide (BD PharMingen), and incubated at room temperature for 15 minutes. Percentages of dead K562 cells were determined by flow cytometry. Cytotoxicities were calculated by subtracting the percentages of dead K562 cells in control tubes from the percentages of dead cells in sample tubes.

\section{RT-PCR}

Total cellular RNA was extracted from isolated BAL cells and NK cells using RNAzol B (Tel-Test, Friendswood, TX), according to the manufacturer's instructions. Aliquots $(3 \mu \mathrm{g})$ of total cellular RNA were transcribed into complementary DNA (cDNA) at $37^{\circ} \mathrm{C}$ for 1 hour in a total volume of $20 \mu \mathrm{l}$ using 2.5 units of Moloney murine leukemia virus reverse transcriptase (Roche, Germany). Reverse-transcribed cDNA samples were then added to a PCR mixture consisting of $10 \times$ PCR buffer, 0.2 mMdNTPs, 0.5 units of Taq DNA polymerase (Biocare Lab, Tunisia), and 10 pmoles of primers for each gene. The sequences of the primers we used were as follows: for $\beta$-actin, $5^{\prime}$-CTCCTTA ATGTCACGCACGAT-3' (sense) and 5'-GTGGGGCG CCCCAG GCACCA-3' (antisense); for perforin, $5^{\prime}$ CTGCCGTGGATGCCTATG-3' (sense) and $5^{\prime}$-CGGC TCACACTCACAGG-3' (antisense); for granzyme, $5^{\prime}$ TACACACAAGA GCTCCAGAGT-3' (sense) and $5^{\prime}$ GGGGAAGCTCCATAAATGTCACCT-3' (antisense); for CD122, 5'-GGTCACCTGATAGTGGAGAA-3' (sense) and $5^{\prime}$-ACCTGAATCCAATTTCACAG-3' (antisense); for c-Kit, $5^{\prime}$-TTCTTACCAGGTGG CAAAGGGCATGGCT TTCC-3' (sense) and 5'-GTCATACATTTCAGCAGGT
GCGTG TTCAGGGC-3' (antisense); and for Flt-3, $5^{\prime}$ GAGGACTTGAATGTGCTTACA-3' (sense) and $5^{\prime}$-TCC CACAGTAATATTCCATATGA-3' (antisense).

Amplifications were conducted over 28 cycles of $94^{\circ} \mathrm{C}$ for 1 minute (denaturation), $55^{\circ} \mathrm{C}$ for 1 minute (annealing), and $72^{\circ} \mathrm{C}$ for 1 minute (extension). This was followed by an additional extension step at $72^{\circ} \mathrm{C}$ for 10 minutes in a PCR cycler (Bio-Rad, CA). PCR products were subjected to electrophoresis and visualized by ethidium bromide staining. Densities were analyzed versus $\beta$-actin by densitometry using Alpha Ease FC image analysis software (Alpha Innotech, CA). Results are presented as relative gene expression intensities.

\section{Quantification of RORC/FOXP3 (Th17/Treg) ratios}

The expression of mRNA for FOXP3 (Treg) and RORC (Th17) was quantified using the Applied Biosystems 7500 Fast Real-Time PCR System (Applied Biosystems, Foster City, CA, USA) as we have recently reported $[9,12]$. Amplification of cDNA was performed with the TaqMan Universal PCR Master Mix $(2 \times)$, No AmpErase UNG (Applied Biosystems). A reaction volume of $25 \mu \mathrm{l}$ (1.0 $\mu \mathrm{lcDNA}$ ) was amplified for 40 cycles of $10 \mathrm{~s}$ at $95^{\circ} \mathrm{C}$ and $1 \mathrm{~min}$ at $60^{\circ} \mathrm{C}$. All samples were analyzed in duplicate, and transcription expression was calculated as a mean and standard deviation (SD). For quantification of cDNA a five-point serially four-fold diluted standard curve was developed from BAL cell cultures stimulated with phytohaemagglutinin (PHA). The mRNA expression of the $\mathrm{T}$ cell transcription factors was standardized to $18 \mathrm{~S}$ (human rRNA) and all results are expressed as a ratio. A coefficient of variance $<15 \%$ was accepted as maximum variation among duplicates. The intra-assay variance for $18 \mathrm{~S}$ was $4.9 \%$, FOXP3 6.1\%, RORC $6.2 \%$. Samples revealing an undetectable expression in both duplicates in three subsequent analyses were assigned an expression quantity of zero. Primers and probes for FOXP3 forward GTGGCCCG GATGTG AGAA, reverse GCTGCTCCAG AGACTGTACCATCT, probe CCTCAA GCACTGCCAGGCGGAC; 18S forward CGGCTACCA CATCCA AGGAA, reverse GCTGGAATTACCGCGGCT, probe GAGGGCAAGTCTGGTGCCA GCA. HPLCpurified oligonucleotide primers and probes were bought from MedProbe (Oslo, Norway). All in-house designed mRNA amplicons included at least one exonexon boundary to assure specificity (marked in bold in the sequences above), and reaction concentration was optimized prior to analysis of samples.

\section{Statistical analysis}

The percentages of NK cells were log-transformed for purposes of analysis. All comparisons of percentages of NK cells and of cytotoxicity were made by analysis of covariance after adjusting for age and sex using the 
Bonferroni correction for multiple comparisons. Comparisons of CD3-CD122 $2^{+}$cell percentages and of CD122 surface expression rates among NK cells were made by analysis of variance with the Bonferroni correction for multiple comparisons. $P$ less than 0.05 was considered statistically significant. All statistical analyses were performed using SPSS version 14.0 software (SPSS, Chicago, IL).

\section{Results}

\section{Cell analyses and Th17/Treg ratio in bronchoalveolar} lavage

BAL fluids recovered from BD patients were more cellular than those from healthy controls and RA patients , containing significantly greater number of lymphocytes $(P<0.05)$ [Table 1]. Expression of retinoid-related orphan receptor $\mathrm{C}$ (RORC) (Th17) and forkhead box P3 (FOXP3) (Treg) mRNA transcript were studied in BAL cells from $27 \mathrm{BD}$ patients with pulmonary manifestations, 14 RA patients and 23 healthy controls. FOXP3 was expressed at similar levels between $\mathrm{BD}$ patients [1.62 $\pm 0.60 \%]$, RA patients $[1.58 \pm 0.44 \%]$ and healthy controls [1.67 $\pm 0.59 \% ; P=0.85$ and $P=0.77$ ]. In contrast, RORC was highly expressed in BAL of BD patients [1.93 $\pm 0.69 \%]$ compared to that of RA patients $[0.76 \pm$ $0.22 \% ; P=0.0001]$ and of healthy controls $[0.85 \pm$ $0.38 \% ; P=0.0001$ ]. Th17/Treg (RORC/FOXP3) ratio was increased in $\mathrm{BD}$ patients contrasting with values observed in RA patients and in healthy controls (Figure 1).

\section{Reduced numbers of circulating NK cells in BAL cells from BD patients}

The percentages of NK cells in the BAL of BD patients, RA patients and healthy controls were determined by flow cytometry. NK cell percentages were significantly lower in $\mathrm{BD}$ patients $[5.59 \% \pm 2.22 \%]$, than in healthy controls $[12.60 \% \pm 2.36 \% ; P=0.0001]$. NK cells in RA patients $[10.50 \% \pm 2.69 \%]$ were expressed at higher level than in BD patients $[P=0.0001]$. Low and significant difference was found between RA and healthy controls $[P=0.017]$ (Figure 2).

\section{Impaired cytotoxicity of BAL NK cells in BD patients}

To examine the cytotoxic effects of NK cells on K562 cells, BAL from 27 BD patients, 14 RA patients, and 23 healthy controls were used. The cytotoxicities of BAL cells were

Table 1 Differential cell count

\begin{tabular}{lllll}
\hline Diseases & Macrophages & Lymphocytes & Neutrophils & Eosinophils \\
\hline BD $(n=27)$ & $72.5 \pm 7.4$ & $19.7 \pm 4.3^{\dagger}$ & $7.6 \pm 10.9$ & $1.9 \pm 4.3$ \\
RA $(n=14)$ & $72.6 \pm 5.8$ & $14.8 \pm 9.7$ & $10.3 \pm 11.9$ & $2.4 \pm 3.6$ \\
HC $(n=23)$ & $78 \pm 6.8$ & $12.5 \pm 3.4$ & $3.5 \pm 1.4$ & $0.5 \pm 0.7$ \\
\hline
\end{tabular}

BD, Behçet's disease; HC, Healthy control, RA, rheumatoidarthritis. Values are presented as mean $) \pm S D$. $(\dagger)$ : Significance Behçet's disease versus control subjects and RA patients $(P=0.001)$.

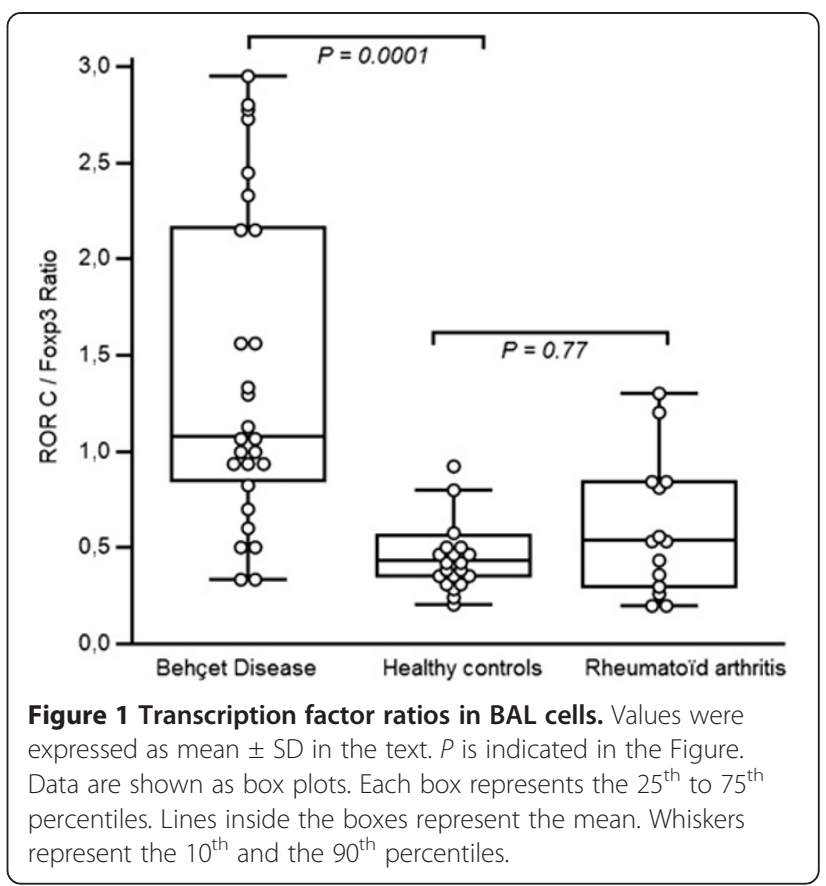

evaluated by flow cytometry and determined at an effector/ target (E:T) cell ratio of 10:1, 5:1 and 2.5:1. The cytotoxicities were significantly lower in BD compared to NK activity in RA patients and in healthy controls (Figure 3A).

Several groups of investigators suggested that NK cytotoxicity was enhanced by IL-2 [19]. LAK activity induced by IL-2 was significantly lower in BD and RA

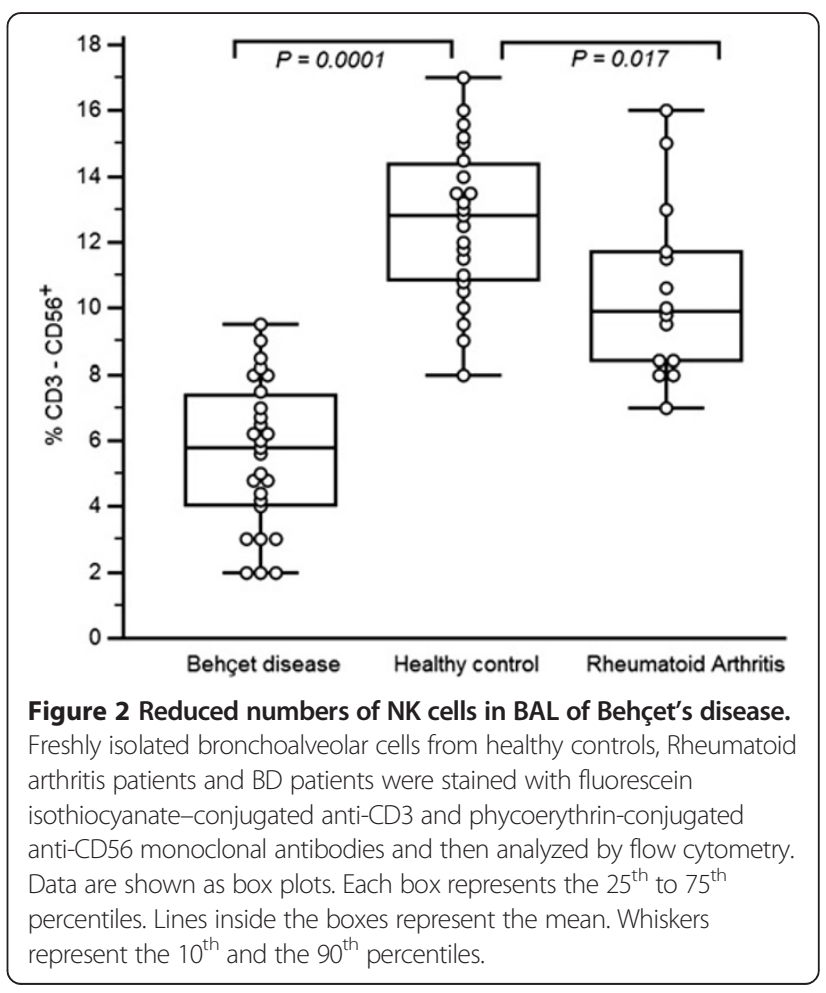



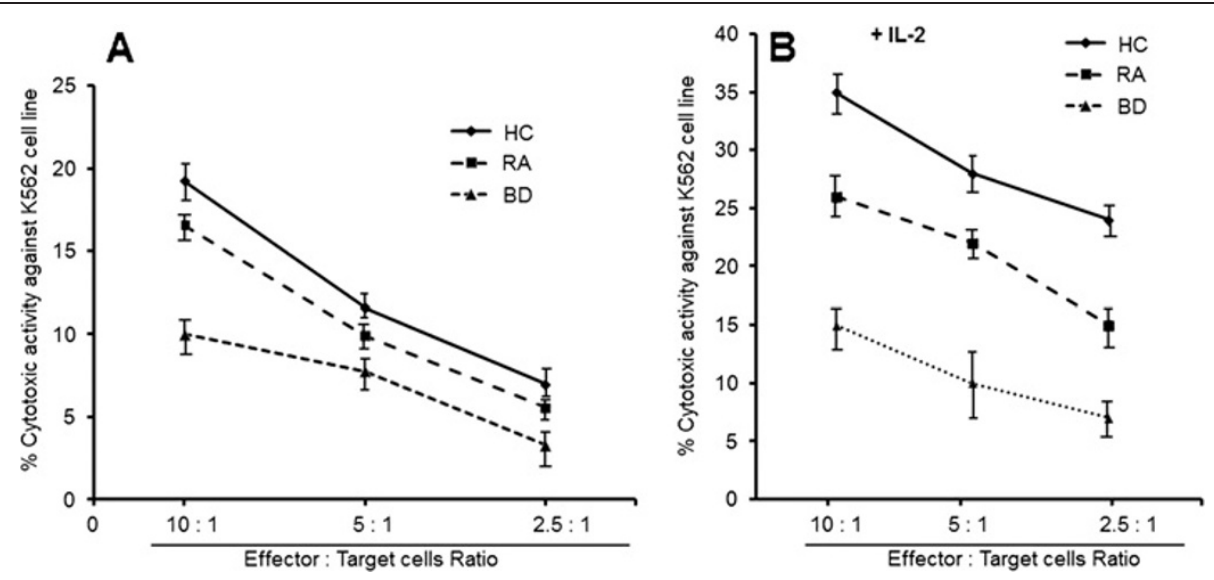

Figure 3 Decreased cytotoxicity of bronchoalveolar lavage cells from Behçet's disease patients. Freshly isolated BAL cells were stained with fluorescein isothiocyanate-conjugated anti-CD45 monoclonal antibody and then cocultured with K562 cells kine for 4 hours. Cytotoxicity was determined as described in patients and methods and is expressed as the percentage of apoptotic K562 cells. For measurement of lymphokine-activated killer (LAK) activity, interleukin-2 (IL-2; $200 \mathrm{IU} / \mathrm{ml}$ ) was added to cocultures. Cytotoxicity [A] and LAK activity [B] were determined in BAL cells from 23 healthy controls (HC), 14 patients with RA and 27 patients with Behçet's disease (BD). Data are Mean \pm SD. Cytotoxicity was determined at an effector-to-target (E:T) cell ratio of 10:1, 5:1 and 2.5: 1.

patients than in healthy controls (Figure 3B). Cytotoxicities of BAL cells were significantly correlated with NK cell percentages [NK activity: $r=0.590 ; P=0.0012$ ]. These findings suggest that impaired cytotoxicity of BAL cells is caused by an NK cell deficiency. Cytotoxicities in BAL from healthy controls were greater at higher E:T cell ratios. This was also the case in BAL from BD and RA patients.

\section{Intrinsic defects of NK cells in BD patients}

To examine whether defective killing by NK cells contributes to the impaired cytotoxicity observed in BD patients, we compared the cytotoxicities of purified NK cells obtained from the BAL of 10 BD patients, 7 RA patients and 10 BAL from healthy controls. The cytotoxicities of purified NK cells were determined at an E:T cell ratio of 10/1, 5:1 and 2.5:1. We found that cytotoxicities and LAK activities were significantly lower in BD patients than in healthy controls. These values were significantly lower in RA patients than in healthy controls (Figures 4A and B). Cytotoxicities and LAK activities increased in healthy controls and RA patients when E:T cell ratios increased, which contrasted in BD patients. These results suggest that killing deficits of NK cells contribute to impaired cytotoxicity and LAK activity in BAL from BD patients.

The expression of IL-2 receptor $\beta$-chain (IL-2R $\beta$, CD122) is important for the differentiation of NK cells. CD122 is regarded as a marker for NK precursors. $\mathrm{CD}^{+} \mathrm{CD} 122^{+}$cells include immature and mature NK cells as reported by Huntington et al. [20]. We investigated the proportions of $\mathrm{CD}^{+} \mathrm{CD} 122^{+}$cells in BAL cells and IL-2R $\beta$-expressing cells in NK cells.
The percentages of $\mathrm{CD}^{+} \mathrm{CD} 122^{+}$cells and of CD122 expression on NK cells were significantly lower in BD patients $\left[\mathrm{CD}^{+}{ }^{+} \mathrm{CD} 122^{+}: 5.32 \pm 1.92 \%, P=0.0001\right.$; CD122-NK cells: $60.70 \pm 13.70, P=0.0001]$ than in RA patients $\left[\mathrm{CD}^{+} \mathrm{CD} 122^{+}\right.$: $18.50 \pm 3.27 \%$; CD122-NK cells: $92.83 \pm 10.11 \%]$ and in healthy controls $\left[\mathrm{CD}^{+} \mathrm{CD} 122^{+}\right.$: $15.10 \pm 3.70 \%$; CD122-NK cells: $84.80 \pm 7.68 \%$; ]. No differences were observed between RA patients and healthy controls $\left[\mathrm{CD}^{+} \mathrm{CD}^{2} 2^{+}: P=0.085 ; P=0.093\right.$ ] (Figures $5 \mathrm{~A}$ and $\mathrm{B})$. We also examined the expression levels of CD122 and of the toxicity-related molecules perforin and granzyme in BAL cells and purified NK cells. Gene transcripts of CD122, perforin, and granzyme were found to be markedly lower in BAL cells and NK cells from BD patients (Figure 5C). Intracellular perforin expression in NK cells was also lower in BD patients than in RA patients and in healthy controls (Figure 5D).

\section{Discussion}

The results of this study demonstrated that BAL cells from BD patients display an inflammatory profile associated with an impairment of NK activity.

The number of Treg cells (FOXP3) was unaltered in $\mathrm{BD}$ patients compared to controls, contrasting with an increase in Th17 (RORC) subpopulation. These results suggest that an imbalance of Th17/Treg in BAL cells may be implicated in the pathogenesis of lung involvement in BD. Increased expression of IL-17 in inflammatory sites supports a Th17-mediated inflammatory pathway in several diseases [21-24].

In the present study, we found that NK cell number and cytotoxicity were decreased in BAL from BD patients with pulmonary involvement compared to RA patients 

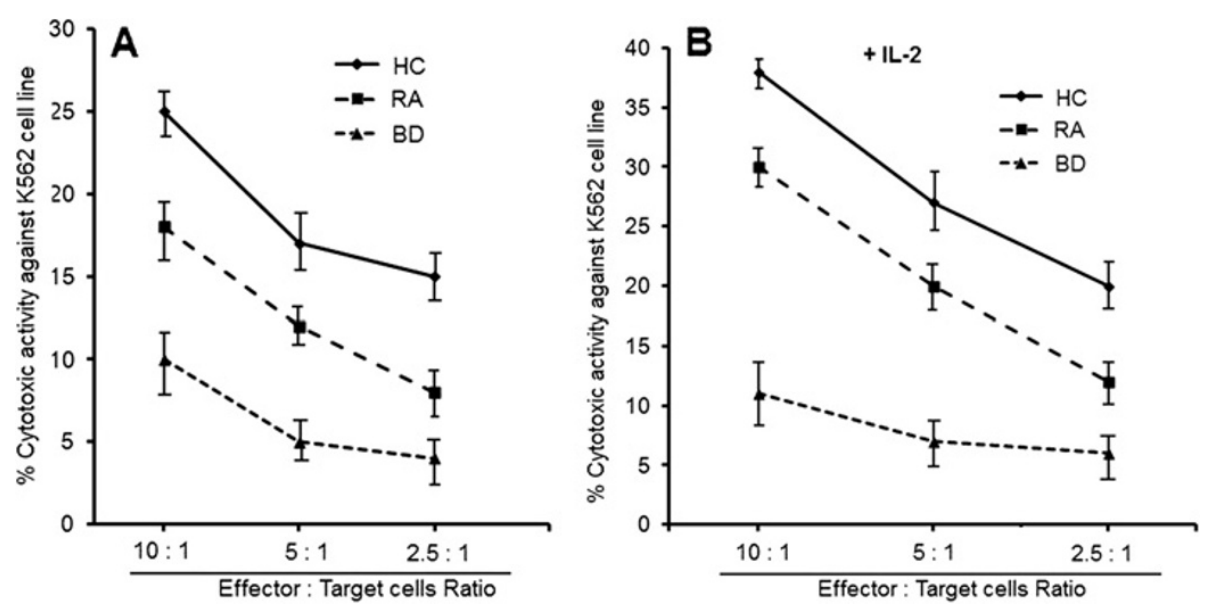

Figure 4 Decreased cytotoxicity of purified natural killer cells from Behçet's disease patients. NK cells were isolated from BAL cells by magnetic-activated cell sorting. Cytotoxicity and lymphokine-activated killer activity were determined as described in Figure 3. Cytotoxicity [A] and LAK activity [B] of purified NK cells were determined in 5 healthy controls, 3 patients with RA and 7 patients with Behçet's Disease. Data are shown as box plots. Each box represents the $25^{\text {th }}$ to $75^{\text {th }}$ percentiles. Lines inside the boxes represent the mean. Whiskers represent the $10^{\text {th }}$ and the $90^{\text {th }}$ percentiles. Cytotoxicity was determined at an effector-to-target (E:T) cell ratio of 10:1, 5:1 and 2.5:1.

and healthy controls. NK cells represent an important population of effector cytotoxic lymphocytes and a major source of pro-inflammatory cytokines. $\mathrm{CD}^{+} \mathrm{CD} 122^{+}$cell, which include immature and mature NK cells [20], were reduced in BAL from BD patients. Cytotoxicity of BAL purified NK cells were markedly suppressed in BD patients. This activity was not diminished in RA patients. Reduction of cytotoxicity in BD patients resulted from a lowered NK cell number associated with an intrinsic NK cell defect of granzyme expression. This is demonstrated by down-regulation of IL-2R $\beta$, perforin, and granzyme in NK cells in our patients.

NK cell numbers and activities were persistently low. These data contrast with reported results on peripheral circulation in BD patients, showing increased NK population and high NK activity [11]. This could raise the question of whether local reductions in NK cell number and activity are a consequence of a defective differentiation of hematopoietic stem cells into NK cells, as recently described by Park et al. in systemic lupus patients [11]. This point has to be investigated in a future report. Intensity and quality of the NK cell cytotoxic response depend on the cytokine microenvironment as well as on immune system interactions $[25,26]$. These interactions include crosstalk between NK cells and dendritic cells (DCs) or $\mathrm{T}$ lymphocytes, occurring initially in secondary compartments such as lymph nodes [27]. The phenotyping and functional results from the present study are partially consistent with these findings.

The reduced cytotoxicity in BAL from BD was merely due to low perforin expression. Resting CD56 ${ }^{\mathrm{dim}} \mathrm{NK}$ cells, which account for the majority of circulating NK cells, express intermediate-affinity IL-2R $\beta$, mediates the induction of LAK activity [28]. In mature NK cells, IL-2R $\beta$ is shared by IL- 2 and IL-15, and IL-15 can efficiently induce NK cell proliferation, differentiation, and activation, which markedly increases NK cytotoxicity. However, adjunction of IL-2 to BD NK cells yielded a reduced increase of cytotoxicity compared to controls. This lowered effect of IL-2 on LAK activity in BD is associated with a decrease in IL-2R $\beta$ expression. As IL-2R $\beta$ is critical for LAK activity and NK cell differentiation, down regulation of IL-2R $\beta$ in NK cells from BD patients is consistent with the reduced response of NK cells to IL-2.

A possible explanation is that NK cell depletion in the BD lung patients occurs secondary to disease progression and to the localized important inflammation existing in the lung. However, our present findings suggest that numerical deficiencies and functional defects of NK cells might play an active role in the pathogenesis of $\mathrm{BD}$, rather than being a consequence of the disease process. Indeed, it has been reported that NK cells may control disease flare/remission in BD patients via NK type 2-mediated modulation of the Th1 response [29].

A possible interaction exists between the increased Th17 and the paucity of NK cells. NK cells are able to down-regulate Th17 cell responses to avoid pathologic autoimmunity. In T-bet $/$ - mice, the paucity of NK and Natural killer T (NKT) cells contributes to a highly polarized Th17 phenotype [30]. Wu et al. [31] demonstrated that addition of NK cells could inhibit T-bet-deficient, autoreactive Th17 cells in the peripheral immune system. These findings have important implications for the development of Th17 cell-mediated autoimmune pathology and suggest a potential role of NK cells in modulation of Th17 cell-mediated autoimmunity. In the lungs of BD 


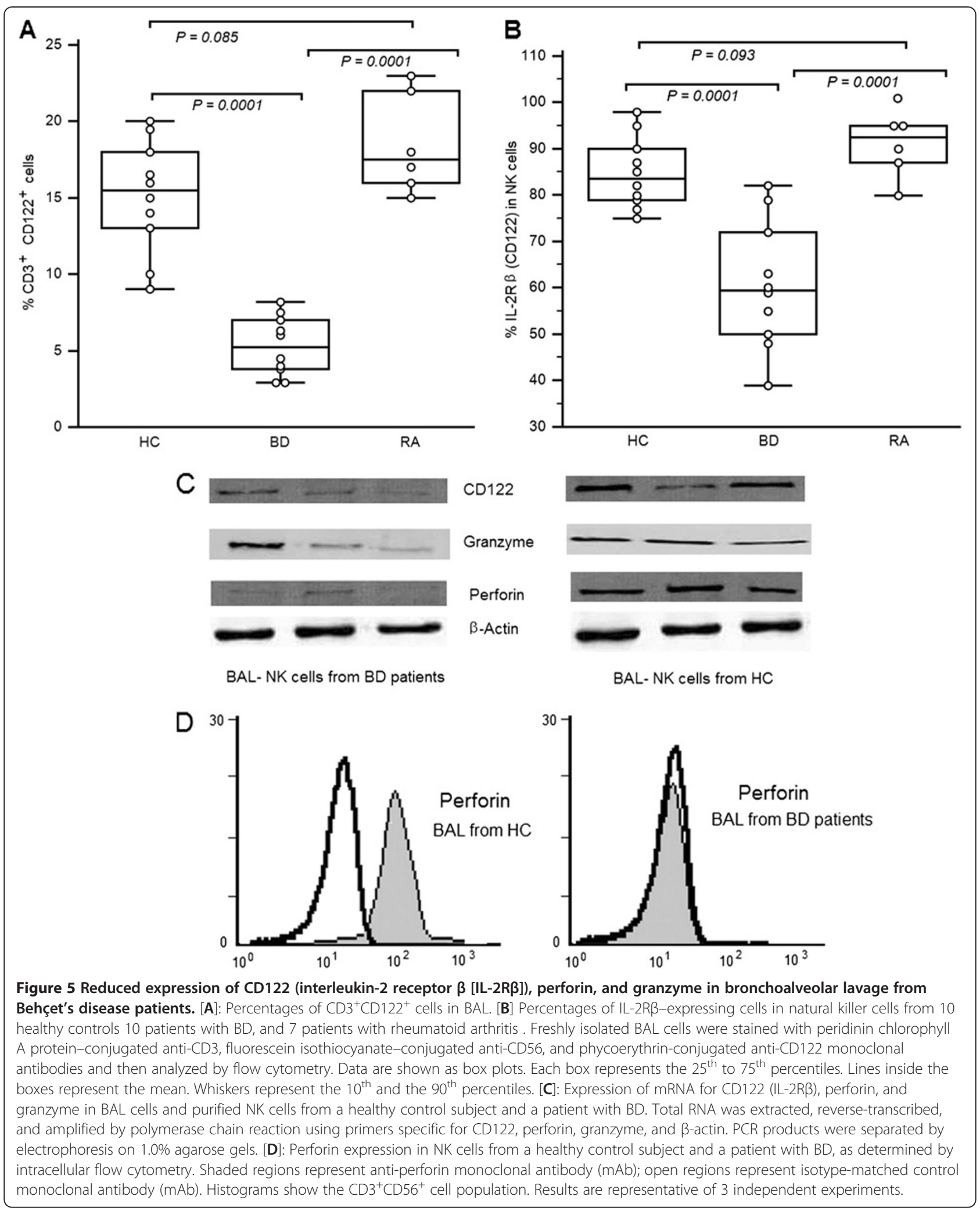


patients the paucity of NK cells is associated with a high Th17 expression. The question remains about IL-17 effect on NK cells.

\section{Conclusions}

Pulmonary manifestations are seen in approximately 25$30 \%$ of BD patients and represent the first cause of mortality. Our phenotypic and functional findings suggested that BAL-NK cells from BD patients could have an impaired differentiation. Despite the increasing NK cells in peripheral circulation, which contrasted with failing NK cell activity in the lung, a body of research on inflammatory mechanisms in pulmonary manifestations has to be done. It is still uncertain whether the NK cell in the lung is friend or foe.

\section{Competing interest}

The authors have no conflicts of interest to disclose.

\section{Authors' contributions}

$\mathrm{AH}, \mathrm{AB}, \mathrm{WK}$ and $\mathrm{KH}$, participated in the design and coordination of the study and to manuscript writing, performed the experiments and analyzed the data. JA participated in the design, coordination of the study and analyzed the data. All authors read and approved the final manuscript.

\section{Author details}

'Department of Basic Sciences, Division of Histology and Immunology, Medicine School of Tunis, Tunis El Manar University, 15 Rue DjebelLakdar, 1007 Tunis, Tunisia. ${ }^{2}$ Department of respiratory diseases and the Unit Research "Homeostasis and Cell dysfunction (99/08-40), Division of Pulmonology, Tunis El Manar University and A. Mami Hospital, Ariana, Tunisia.

Received: 13 November 2012 Accepted: 28 February 2013 Published: 4 April 2013

\section{References}

1. Mumcu G, Inanc N, Yavuz S, Direskeneli $\mathrm{H}$ : The role of infectious agents in the pathogenesis, clinical manifestations and treatment strategies in Behcet's disease. ClinExpRheumatol 2007, 25:S27-S33.

2. Lehner T, Lavery E, Smith R, Van der-Zee R, Mizushima Y, Shinnick T: Association between the $65 \mathrm{kDa}$ heat shock protein, Streptoccocussanguis and the corresponding antibodies in Behcet's syndrome. Infect Immun 1991 , 59:1434-1441.

3. Hamzaoui K, Hamzaoui A: Immunological responses in patients with behçets disease: advances in understanding. Expert Rev Ophthalmol 2012, 7(3):261-270.

4. Pay S, Simşek I, Erdem H, Dinç A: Immunopathogenesis of Behçet's disease with special emphasize on the possible role of antigen presenting cells. Rheumatollnt 2007, 27:417-424.

5. Ozkaya S, Sengul B, Hamsici S, Findik S, Sahin U, Gumus A, Cinarka H: Right sided arcus aorta as a cause of dyspnea and chronic cough. Multidiscip Respir Med 2012, 7(1):37.

6. Yılmaz S, Cimen KA: Pulmonary artery aneurysms in Behçet's disease. Rheumatollnt 2010, 30:1401-1403.

7. Hamzaoui A, Haj Sassi F, Hamzaoui K: Release of B cell-activating factor of the TNF family in bronchoalveolar lavage from Behçet's disease with pulmonary involvement. Oxid Med Cell Longev 2010, 3(2):122-128.

8. Hamzaoui A, Ghraïri H, Ammar J, Zekri S, Guemira F, Hamzaoui K: IL-18 mRNA expression and IFN-gamma induction in bronchoalveolar lavage from Behçet's disease. Clin Exp Rheumatol 2003, 21(4 Suppl 30):S8-S14.

9. Hamzaoui K, Abid H, Berraies A, Ammar J, Hamzaoui A: NOD2 is highly expressed in Behçet disease with pulmonary manifestations. J Inflamm (Lond) 2012, 13(1):3.

10. Tian Z, Gershwin ME, Zhang C: Regulatory NK cells in autoimmune disease. J Autoimmun 2012, 39(3):206-215.

11. Park YW, Kee SJ, Cho YN, Lee EH, Lee HY, Kim EM, Shin MH, Park JJ, Kim TJ, Lee SS, Yoo DH, Kang HS: Impaired differentiation and cytotoxicity of natural killer cells in systemic lupus erythematosus. Arthritis Rheum 2009, 60(6):1753-1763.

12. Hamzaoui K, Kamoun M, Houman H, Hentati F, Hamza M, Ayed K, Hamzaoui A Discrepancies of NKT cells expression in peripheral blood and in cerebrospinal fluid from Behçet's disease. J Neuroimmunol 2006, 175(1-2):160-168.

13. Ahn JK, Chung H, Lee DS, Yu YS, Yu HG: CD $8^{\text {bright }} \mathrm{CD} 56^{+} \mathrm{T}$ cells are cytotoxic effectors in patients with active Behcet's uveitis. J Immunol 2005, 175:6133-6142.

14. Kibaroglu A, Eksioglu-Demiralp E, Akoglu T, Direskeneli H: T and NK cell subset changes with microbial extracts and human HSP60-derived peptides in Behçet's disease. Clin Exp Rheumatol 2004, 22(4 Suppl 34):S59-S63.

15. Arayssi TK, El Hajj N, Shamseddine W, Ibrahim G, Nasr J, Sabbagh AS, Greige L, Zaatari GS, Mahfouz RA: Killer cell immunoglobulin-like receptor genotypes in Behçet's disease patients: any role for the 3DP1*001/002 pseudogene? Genet Test Mol Biomarkers 2009, 13(3):319-324.

16. Seo J, Park JS, Nam JH, Bang D, Sohn S, Lee ES, Park KS: Association of CD94/NKG2A, CD94/NKG2C, and its ligand HLA-E polymorphisms with Behcet's disease. Tissue Antigens 2007, 70(4):307-313.

17. International study group for Behcet's disease: Criteria for diagnosis of Behcet's disease. Lancet 1990, 335:1078-1080.

18. American Thoracic Society, European Respiratory Society and World Association of Sarcoidosis and Other Granulomatous Disorders: Joint statement on sarcoidosis. Am J Respir Crit Care Med 1999, 160:736-755.

19. Lee $\mathrm{SH}$, Fragoso MF, Biron CA: Cutting edge: a novel mechanism bridging innate and adaptive immunity: IL-12 induction of CD25 to form highaffinity IL-2 receptors on NK cells. J Immunol 2012, 189(6):2712-2716.

20. Huntington ND, Vosshenrich CA, Di Santo JP: Developmental pathways that generate natural-killer-cell diversity in mice and humans. Nat Rev Immunol 2007, 7:703-714.

21. Cañete JD, Celis R, Noordenbos T, Moll C, Gómez-Puerta JA, Pizcueta P, Palacin A, Tak PP, Sanmartí R, Baeten D: Distinct synovial immunopathology in Behçet disease and psoriatic arthritis. Arthritis Res Ther 2009, 11:R17.

22. Ekinci NS, Alpsoy E, Karakas AA, Yilmaz SB, Yegin O: IL-17A has an important role in the acute attacks of Behçet's disease. J Invest Dermatol 2010, 130:2136-2138.

23. Usui Y, Takeuchi M, Yamakawa N, Takeuchi A, Kezuka T, Ma J, Matsuda R, Okunuki Y, Akiba H, Goto H: Expression and function of inducible costimulator on peripheral blood CD4+ T cells in Behçet's patients with uveitis: a new activity marker? Invest Ophthalmol Vis Sci 2010, 51:5099-5104.

24. Saruhan-Direskeneli G, Yentür SP, Akman-Demir G, Işik N, Serdaroğlu P: Cytokines and chemokines in neuro-Behçet's disease compared to multiple sclerosis and other neurological diseases. J Neuroimmunol 2003, 145:127-134.

25. Roth C, Rothlin C, Riou S, Raulet DH, Lemke G: Stromal-cell regulation of natural killer cell differentiation. J Mol Med 2007, 85:1047-1056.

26. Lucas M, Schachterle W, Oberle K, Aichele P, Diefenbach A: Dendritic cells prime natural killer cells by trans-presenting interleukin 15. Immunity 2007, 26:503-517.

27. Ferlazzo G, Pack M, Thomas D, Paludan C, Schmid D, Strowig T, Bougras G, Muller WA, Moretta L, Münz C: Distinct roles of IL-12 and IL-15 in human natural killer cell activation by dendritic cells from secondary lymphoid organs. Proc Natl Acad Sci U S A 2004, 101:16606-16611.

28. Siegel JP, Sharon M, Smith PL, Leonard WJ: The IL-2 receptor $\beta$ chain (p70): role in mediating signals for LAK, NK, and proliferative activities. Science 1987, 238:75-78

29. Yamaguchi Y, Takahashi H, Satoh T, Okazaki Y, Mizuki N, Takahashi K Ikezawa Z, Kuwana M: Natural killer cells control a T-helper 1 response in patients with Behçet's disease. Arthritis Res Ther 2010, 12(3):R80.

30. Townsend MJ, Weinmann AS, Matsuda $J \mathrm{~L}$, et al: T-bet regulates the terminal maturation and homeostasis of NK and Valpha14i NKT cells. Immunity 2004, 20:477-494.

31. Wu W, Shi S, Ljunggren HG, Cava AL, Van Kaer L, Shi FD, Liu R: NK cells inhibit T-bet-deficient, autoreactive Th17 cells. Scand J Immunol 2012, 76(6):559-566.

doi:10.1186/2049-6958-8-29

Cite this article as: Hamzaoui et al:: Pulmonary manifestations in Behçet disease: impaired natural killer cells activity. Multidisciplinary Respiratory Medicine 2013 8:29. 